\title{
Paul Leni's Waxworks: Writing Images from Silence, through Media and Philosophy
}

\author{
Ciro Inácio Marcondes \\ Universidade de Brasília (Brazil) \\ E-mail: ciroimarcondes@hotmail.com
}

\begin{abstract}
The so-called German Weimar Cinema encompasses a profusion of films that used frame narratives. In the case of Paul Leni's Waxworks (Das Wachsfigurenkabinett, 1924), as the framing stems from a literary act (the stories are framed by the act of narration), the film proposes the mise-enabyme technique as a sort of immersion into the intermedial when it deals with notions like speaking, writing, silence, image and cinema. In the case of silent cinema, and especially in Waxworks, the presence of a perverse relation with the medium of writing becomes noticeable (producing a fantasy of writing), since every effort to represent the literary act on film results in an infinite production of silent images, creating a parody effect and even postulating an act of aggression against writing. This confrontational relation between the writing code and the code of the mute image in silent cinema allows us to suggest that there is an inherent inflexibility in the language of silent cinema which does not allow the coexistence of written and spoken word as complementary codes. On the contrary, in silent cinema, the image and the silence of the film seem to work against the word, the spoken word being set forth against silence, and the written word against images.
\end{abstract}

Keywords: Paul Leni, Waxworks, German expressionism, Derrida, silence, writing, intermediality.

In a frame story, texts are layered inside other texts by means of narration and sub-narration procedures. A narrating voice delegates narration to another narrating voice, usually within its own diegesis, turning the narrative into an iterative process along which the spectator must elaborate a deeper reading of those delegation instances so that the formal scales of content may be understood. The most famous example of using a frame story is the Arabian Nights, or One Thousand and One Nights, in which an omniscient narrator relates the tale of Sheherazade, who, by virtue of the plot itself, must tell myriad other tales ("one thousand and one") and assumes a second narrating voice as a character herself. 
The tales told by Sheherazade also include moments in which the characters go on to tell their own tales, either by means of simple dialogue (which are always delegated narrations) or actual embedded narratives. In this case, we may then perceive three degrees of narration interspersed with one another and, as we are dealing with literature in this particular case, they are all duly verbalized and replace each other's narrative making use of the linguistic code.

There are traces of frame stories in different kinds of cinema, when one particular representation mode gets inserted within the overall mode of representation of the movie. Such is the case, for instance, of Children of Paradise (Les enfants du paradis, Marcel Carné, 1945); we come across, throughout the movie, different modes of mise-en-abyme, in which one representation takes place within another. In this particular case, it is a theatrical representation that takes place within the cinematographic representation. We can consider the sum of all representational devices in film a mega-narrator. According to André Gaudreault, this is an instance that comprises all the narrative attributes of sound, image and montage in a film. Nevertheless, the theatre play in Children of Paradise is not delegated in the technical sense as the play technically does not narrate but shows. Gaudreault and Jost (2005) specifically distinguish the phenomena of showing and narrating as two different models of representation. Showing, in this case, which also belongs in cinema (however, tied to a narration operated by filmic instances), is self-narrated (or shown by an instrument of showing operating on photogram not on shot - level). It can do without an organizing instance. It would be pure representation; immediate mimesis.

In a silent movie such as Waxworks (Das Wachsfigurenkabinett, Paul Leni, 1924), however, the mise-en-abyme happens within a process of narrative delegation, and comprising not only instances of filmed theatre. Not being specific at any level of silent movies, this can happen, of course, in the case of spoken movies as well -, such as, famously, Citizen Kane (Orson Welles, 1940). However, we are interested in focusing on this aspect of Waxworks as it is decisive for the establishment of a relationship between words and silence in the movie itself. First of all, though, it is befitting to layout some context regarding the time and conditions under which the movie was produced, as well as the movie that inspired it, The Cabinet of Dr. Caligari (Das Cabinet des Dr. Caligari, Robert Wiene, 1919).

Waxworks was produced in 1924, at the height of the German silent movie industry, which, at that point, consolidated a productivity that encompassed both the internal market (with genre movies, more to the taste of the population) 
and the external market (with famous super-productions such as Metropolis [Fritz Lang, 1927], Die Nibelungen: Siegfried [Fritz Lang, 1924] and Faust [Faust - Eine Deutsche Volkssage, F. W. Murnau, 1926], intended as competition with Hollywood). This industry catapulted its own star system to the highest popularity, especially artists from the two largest companies, UFA and Emelka. Waxworks was released by Neptune but distributed by the giant UFA, known for mixing up the concepts of art house with popular movie, going for a quintessential and refined quality but also for box office success. This concept of art house movie (or autorenfilm, "author cinema") ended up being historically associated to that of German expressionism, which, in its initial form, did not keep after 1922, giving way to other genres such as kammerspiel, a type of everyman cinema geared toward the working classes that became the main audience in Germany in the 1920s. A more properly encompassing scenario would range from The Student of Prague (Der Student von Prag, Stellan Rye, 1913) to Berlin: Symphony of a Great City (Berlin: Die Sinfonie der Großstadt, Walter Ruttmann, 1927) under the umbrella of Weimar cinema (Elsaesser 2000), referring to the Republic that followed Wilhelmine Germany and preceded the rise of the Nazi regime. The term expressionism, however, is important here as Waxworks may be considered one of the main Weimar movies that explicitly referenced this type of cinema. In this case, it is at once homage and parody.

Regarding expressionism, ${ }^{1}$ we might rightfully think that narrative distortion was one of the specific features of this kind of cinema, beside moral distortion and degeneracy (madness, murder, suicide) as well as visual distortion (set deformation, radical photography effects, oblique montage). This narrative distortion might have seemed very odd to American audiences precisely because it did not create solid references in terms of the characters' characterization and motivation. In Weimar movies, murder, domination, subjugation and control stories frequently appeared with no visible motivation. Entire narrative sections went by without any hypotheses of plot background being created, without the chance for the viewer to create a link of predictability between themselves and the movie. Such are, for instance, the brutal and apparently mindless acts in The Cabinet of Dr. Caligari, which seem to transmute into one another as if the images were variations, without the logical effect of narratives. Those mesmerizing and controlling effects which appear in classics such as Nosferatu (Nosferatu, Eine Symphonie des Grauens, F.W. Murnau, 1922) and Dr. Mabuse: the Gambler (Dr.

1 For a broader debate about the readings on Weimar cinema, see Eisner (2008), Kracauer (2004), as well as the extensive review in Elsaesser (2000) and Garncarz (2004). 
Mabuse, der Spieler, Fritz Lang, 1922) are ascribed in the films to the psyche or to technology. This generated several interpretations involving media theories, psychoanalysis, mass culture, etc. The lack of control over the characters' actions and the consequences of these are often embedded in the very narrative function of the movie, as is the case of the frame stories present in The Student of Prague, in The Cabinet of Dr. Caligari as well as in Destiny (Der müde Tod, Fritz Lang, 1921) and, of course, in Waxworks.

However, according to an extensive analysis by Elsaesser (2000, 61-105), the frame story in The Cabinet of Dr. Caligari, the original nature of which is revealed to us only by the end of the film, is more at the service of confounding the audience and adding sinister elements of dubious interpretation than actually framing the story, that is, placing it within clearer frames. As the movie starts, we see young Francis giving an account of the incredible adventure he lived while helping capture the malevolent Dr. Caligari and his sleepwalking assistant, the assassin Cesare. We see the whole story emerging as a flashback from Francis's memory (hence the frame) and, as it ends, we return to the initial narrative and find out that Francis is in an asylum. The physiognomy he was associating to Caligari is actually that of his doctor. Waxworks is a clear parody of Caligari; the connection between the two is signaled not only by the former's title, which, too, contains the word cabinet (in its original German: Das Wachsfigurenkabinett), but there is also the presence of a frame story that serves multiple purposes, one of which being the combination of fiction within fiction, drawing attention to the very act of telling stories ("narrating"). This movie has also been inspired by the hit Destiny, which, also set within a frame, tells the story of a woman who seeks out Death itself in an attempt to bring her husband back to life. Death, then, challenges her to save three people who are perishing in different times and places before rewarding her with the resurrection of her husband. With the woman's story as the frame, the movie goes on narrating her three challenges, returning, of course, to the perspective of the frame by the end of the film.

The frame in Waxworks, similar to that in Destiny (as it also contains three other stories) arises from a literary act, and therein lies the focus of our interest. As the movie begins, we are at a circus and we witness the arrival of a writer to a tent with in which wax statues stand [Fig. 1]. He has answered an ad looking for a talented person to write a publicity piece for the business. The writer (William Dieterle), whose name we never learn, arrives at the tent, a sinister and suffocating setting, and, at once, meets the owner, a disheveled Caligariesque character, and his beautiful daughter, with whom he flirts briefly [Fig. 2]. The owner shows him 
some of his wax figures and offers him the opportunity of writing scary tales about them. The figures represent historical characters: Harun Al-Rashid (Emil Jannings, [Fig. 3.]), the famous caliph of Baghdad from the Middle Ages; the tyrannical Russian Czar Ivan the Terrible (Conrad Veidt, [Fig. 4.]); and Victorian psychopath Jack the Ripper (Werner Krauss, [Fig. 5]). The writer then goes on to produce a tale for each of the statues [Fig. 6.], and the filmic narration is in charge of translating these into images. Our first stop is the medieval Baghdad, where we witness how Harun Al-Rashid loses and arm, then we move on to Ivan's Russia and witness his atrocities. The ending, however, has a surprise in store for the audience.

As made evident, Waxworks imitates Dr. Caligari as it employs the same actors (that is, Veidt and Krauss - true celebrities at the time) ${ }^{2}$ and a similar narrative structure. It is noteworthy how the present of the writer and the present of the images of the historical characters is treated. They are tied together in this narrative stroke that is the frame, yielding a strange structure of visualization of the literariness proposed by the movie, risking a replacement of the written discourse (which, by its own nature, already is the substitute of spoken discourse) with a visual/cinematographic discourse. The latter is not only silent, but also hallucinatory, deformative, grotesque, delirious in an expressionist fashion, with an exotic touch of orientalism. It is as if by mere replacement of writing with image, the voice originating from speech became murky, skewed and outcast from explicit rationality.

What catches our attention in this movie, in contrast with others that also employ frame stories, is that in this case, the frame serves not only to correlate themes and pour the words created by the writer onto cinematic images (which, somehow, replicates the frame motif in itself), but also serves to create another frame, this time an intermediary one, to set writing (in this case, literature) within cinema. Thinking of McLuhan (1994), it would be a strange device for a movie to process writing within its boundaries, as it brings to the fore a reflection about media. And that is not all. Much like the scene with Thatcher's records in Citizen Kane, a movie broadly influenced by expressionist aesthetics (Gaudreault and Jost 2005, 71-73), a scriptural record, represented by the writer's own quill inside

2 German stars were generally recognized as noble ones, coming from the theatrical dramaturgy, and carrying an aura of discretion, respectability and decency. "Even though the US and German star system of the 1920s served the same function, namely to lure movie-goers to the cinema, the two systems reached their goal with different means. German stars displayed culturally distinctive lifestyles, attitudes and fashions. Their success was based on cultural traditions familiar to German audiences, and they represented attitudes and interests that were specific to Germany." (Garncarz 2004, 392.) 
the tent, is replaced by a cinematographic narrative. All that is being written down by the writer, instead of getting transposed into another written code (such as in the Arabian Nights) - which could function as a substitute -, is translated into and visualized as cinematographic code. This process includes the omission of a series of elements (including linguistic minutiae) which are detailed in the original code, in the writing, as well as the incorporation of others that were not originally in the text. The transformation of one register into another has to deal with the quandaries of an intermedial translation. That involves thinking about the nature of the communicative instances involved in the discursive processing of this movie: speech, writing, silence, image and the cinematic device itself.

Regarding the silent nature itself of silent film, it is important to note that there is controversy about both the sound diversity that existed in the first film shows (voices, sound effects, commentators, screams from the audience and, certainly, music) as well as about the silence inherent to the conditions of perception of these films, since the diegetic world of these was neither deaf nor mute, even the actors' lines - as Isabelle Raynauld $(2001,70)$ proves - were scripted, rehearsed and staged during the filming. Where lies, therefore, the silence of silent cinema? While there is consensus on the various sound modes that made up the different phases and times of silent cinema, Rick Altman stresses (Szaloky 2002, 111) that many of the sessions of silent cinema, especially in the so-called early cinema, were displayed effectively without any sound accompaniment. Researcher Martin Barnier, after thorough examination of French cinema until 1914, finds the results inconclusive: "[t]he strong overlap between the café-concert and 'Cinema' allows us to say that the songs and the chantings around films had a great focus on the way that films were perceived [...] The accompaniment by sound effects and the commentator [...] also concerns us. The frequency of intervention of these sounds and voices in the projections is still difficult to assess. Very few newspapers refer to these two elements" (Barnier 2010, 17).

Moreover, beyond a technical debate about the presence of sound elements in various stages of silent cinema, Melinda Szaloky argues that even if there was no accompaniment or sound synchronization in these films, a whole universe of sound was present in them through a kind of metaphorical kinaesthesia, when we intuit the sound (even the inexistent one) through our bodily experience of deriving a sense from other senses (in this case, hearing from viewing). "We may consider the silence of the film from the standpoint of the medium itself where the medium is defined not in terms of its material technology but as a representational practice directed toward reception by spectators" (Szaloky 2002, 111). 
Despite all this argumentation, and in defence of the maintenance of silence in silent cinema, we cannot dodge a certain truism: namely that even though the characters are not deaf and mute (and the films are not diegetically silent), even if there was noise and music accompanying the film, and even if we can "hear" what the characters say through a synaesthetic inner ear, these movies themselves were and are technically silent. Dialogues and sounds suggested in these images are pure virtuality and as such exposed to ambiguity. If there is a tendency to take advantage of this virtual environment and build a sound world that technically does not exist, then it is possible to look at the other side and also enhance the silent environment inherent to the technical nature of these films, making its mediatic nature influence its perceptual nature, as well as the spectators' cognitive reception.

The above argument, which seeks to set aside the silence of silent cinema, seems to lack the possibility to appreciate this silence as a technical attribute that necessarily changes both the film's aesthetic and narrative formats, as well as the viewer's perception as compared to sound film. In short, as a consequence of this argument we lose the intrinsic value of silence and the effects that the cinematic image has when it appears silent. Based on the philosopher Max Picard, Cheryl Glenn reinforces the valence of silence while elaborating on its ambiguity in relation to speech (and the interdependence of each other): "Picard explains our dilemma: 'One cannot imagine a world in which there is nothing but language and speech, but one can imagine a world where there is nothing but silence. Silence contains everything in itself. It is not waiting for anything; it is always wholly in itself and it completely fills out the space in which it appears'. Containing everything in itself, silence is meaningful, even if it is invisible. It can mean powerlessness or emptiness - but not always. Because it fills out the space in which it appears, it can be equated with a kind of emptiness, but this is not the same as absence. And silencing, for that matter, is not the same as erasing. Like the zero in mathematics, silence is an absence with a function, and a rhetorical one at that" $(2004,4)$.

If, as argued by Glenn, silence assigns a mathematical function to speech, what happens to the image that takes on this function? Or even to music, which accompanied many of these films? If thought and mind are circuits that function as perceptual frequencies, what happens when we replace a circuit of words and logocentric perceptions with a musical circuit? As discussed by the Argentinean philosopher Santiago Kovadloff, at this moment, music is equivalent to silence: "[m]y initial intention is to recognize music as synonymous with silence; the extreme silence as a musical sound. Because if silence is not necessarily the absence of sound, but the presence of a sense that exceeds our understanding, then 
music can be the expression of silence. What does listening to silence mean if not listening to what fails to be said?" (Kovadloff 2003, 75). We can think therefore within the frameworks of a broad concept of silence; and looking at the inherent influence of silence on silent film, the problem we seek to understand is how this technical attribute transforms the filmic image into the viewers' experience.

Derrida, in his Grammatology (1998), tries to deconstruct Lévi-Strauss's theory of écriture (literally, "scripture"), according to which the foremost function of written communication would be to "enslave and subordinate," as opposed to the "natural" quality of speech, connected directly to humanity itself. Derrida treats écriture as a kind of violence that precedes the invention of writing (hence the need to use a distinct word). The process of naming things already pertains, in an originating instance (Derrida's archiscripture), to the creation of difference, that is, to separating the world in itself, to establishing the act of postulation. Therein lies the birth of law, morals and cultural codes. What Lévi-Strauss sees as violence against a certain natural, idyllic and "true" state that is speech, Derrida sees as an inevitable facility in itself, putting écriture in a place of precedence to speech, necessarily correlating violence, écriture and difference. Violence, in this case, is the inaugural act that covers up the "essential" origins sought by Lévi-Strauss. As those origins erase their own traces, they can rightly serve as desecrated origins, with the knowledge that they are not original, and functioning at once as their own prosthetics and the negation of their own existence. A phantom limb, the Derridean inscription perpetuates a cul-de-sac in the relationship between image and words, admitting precedence to writing but at the same time assuming that this precedence can only be detected by its traces, naturally impossible to be viewed. "The scripture, in its daily life meaning, the common use of the word, dependent as it is of the entry of a surface, the violent incision and separation of a medium (even the projection of characters on a computer screen is not a passive process) works, thus, as a model of this inscription more fundamentally violent that Derrida called above the 'archiscripture.' It is clear that the speech - the voice - can't serve as a model for such process: according to the traditional system (logo and phonocentric) of representation which opposes speech and scripture, the speech is transmitted by the transparent medium and not printable air, it leaves no trace; it is the ideal and immediate mediation of the soul, meanwhile the scripture dwells the external and corporeal realm of matter. Simply put, it may be said that violence is (arch-) scripture is difference." (Johnson 2001, 33.)

If we trust Derrida to consider écriture as a foundational violence that performs the feat of erasing its own traces as well as the origin of its precedence, we are 
entering into a terrain of silence. The Derridean trail leads to a formulation of silence that is absolutely inextricable, unattainable and ineffable. If the écriture is a violation, the only category that can be thought of in terms of something to be violated is silence. And the insertion of the theme of writing into Waxworks, set off by the intermediary phagocytosis promoted by the dimensions of miseen-abyme, leads to some considerations about the possibilities of silence in the movie. Such is, in particular, an ironic use of the same writing, shaped into a narrative Russian doll that transforms the symbolic character of words into a spilled cauldron of signs and hallucinations. This process includes settings ravaged by deformity, images that come to life, thoughts that turn into narratives and dreams made real to haunt the living.

Silence in Waxworks, therefore, according to a Derridean logic, is not a return to an idyllic state (being itself the place of Eden, replacing the concept of speech in Lévi-Strauss) where everything works in peace, and which is absent from the areas of writing and sound. Silence (from which the Derridean trail emerges) is a space of conflict, by being at every moment one step closer to inaugurating archiscripture, which nominates and puts order in the world again. A silent film, due to its stubborn return to this instance, is continuously insisting on looking back, on seeking the incommunicable, on walking this fading trail again. It is a medium, therefore, opposed to sound pictures, which seek to move forward and communicate in a logocentric way. Waxworks has the merit of questioning the vicissitudes of this opposition of media within their own themes and narratives. On the one hand, we have the writer looking to rationalize those images of wax and putting them in an evolutionary and logical order. On the other hand, all instances of the film (its edition, performances, art direction) seek to validate silence and its unrecoverable trace - like a truly original chaotic scenario. And it is precisely in this conflict where the power of the film lies.

Without lingering on a theory of image, we can move on to the recognition that the relationship between imagining writing (through the writer's character) and the act of shaping it into a cinematographic narrative is largely rooted in irony. First of all, there is the break, typical of the expressionist narrative, associated to the process of writing. The writer himself seems stuck to a layer of timelessness, implausible when it comes to causal narrative: he remains in the tent as he writes, as if there was no obvious need for changes in time in storytelling and in the narrative continuity of any given movie. Time and space, in the stories viewed through the frame, seem constantly obliterated - rather effectively as part of a dream. Here, symbolic elements stemming from the unconscious, after being condensed 
and dislodged, are more important than any kind of causal sequencing. "The symbolic code blocks discursive mastery on the part of the spectator, in contrast to the illusion of narrative control the audience enjoys in the classical Hollywood cinema, for example, by often knowing more than the characters. Compared to this classical storytelling, whose compliance with the spectator's desire "to see and to know" makes it appear invisible, Weimar films often foreground the question of who authorizes or controls the act of narration. The profusion of nested narratives, framed tales, flashbacks, mise-en-abyme constructions and interlacing of narrative voices is an index of the differences that established German silent cinema as historically specific." (Elsaesser 2000, 81-82.)

As it is shown by the ambiguous nature itself of the relationship between speech, silence and writing (especially from Derrida on), the transformation of a written and verbal discourse into a discourse of images and silence in Waxworks does not happen exactly as an inversion of the relationship between speech and silence. Here, first of all, there is no true speech, and very little writing. There is no source text, as is a case of adaptations. Everything truly happens within a fantasy of writing. We can talk about images that dream of being written, silence that dreams of having voice. Everything we perceive in the movie is shaped into images that connote writing: images of the writer, images of the writer writing, and even images of the writer's writing itself. It bears remembering that writing is also made of images, and, in a silent film, the appearance of writing on placards acquires an aesthetic sense. Those images dynamically generate other images almost spontaneously, precisely because they are propelled by the writing/image and speech/silence relationships that are set off by the essential elements that comprise the structure and plot of the movie. In Waxworks, speech does not exist, technically, and those two systems (silence and speech) somehow orbit each other but never touch. Hence, everything pertaining to speech resides only in the quandaries of the placards, and everything pertaining to writing is but a dream of the image represented by the writer himself.

Much the same way as speech seeks to return to the pre-linguistic silence that oriented our ancestors, spoken cinema seeks to return to silent movies, whether through a transposition of this principle or by inter-relations across media. A silent movie such as Waxworks seeks to dwell on the silent ambience that is the Derridean trail. If écriture establishes the human, and everything else is silence, then silent film, by mimicking structures, equalling representation powers, distorting and contorting its own possibilities, also seeks to return to this fading trail. It seeks to $d w e l l$ on it, even when it is unable to represent it. Hence, finally, the natural trading floor that is built between silence and image, is yielding to the 
natural silent fortress of silent movies. This configuration vilifies and expurgates the insertion of words (as opposed to images) and speech (as opposed to silence), consummating its language by the cognitive process of poetry.

This almost intuitive association of image (disconnected from words) with silence that catalyzes the aesthetic and cognitive reception processes in silent film is demonstrated, in Waxworks, through the wax figures' coming to life. After all, we must not forget that the wax figures of Harun Al-Rashid, Ivan the Terrible and Jack the Ripper are, for the film, images of those characters. Each of those static images, processed in the writer's mind, become living images. They will silently penetrate the almost eldritch settings, product of a readily oneiric and deformative imagination (typical of expressionism), which will also be created by the image of the writer. In this case, images emerge from images, transforming the expressionist panorama of the film into something disconnected from reality. This is true not only in the sense that it is a product of fiction (which is intellectual), but also in the point of view that the absence of the world of sound obliges all visual aspects of the film to dialogue with one another from a perspective that emerges from the pictorial. Thus, the exaggerated and grotesque performances are extensions of the geometric settings, as if all of the film's visual code followed a clear path away from the imprisoning and regulatory reality of the world of sound (cf. Chion 2005, 7-12). As argued by Bordwell and Thompson when discussing expressionist aesthetics: "German Expressionism depends heavily on mise-en-scène. Shapes are distorted and exaggerated unrealistically for expressive purposes. Actors often wear heavy makeup and move in jerky or slow, sinuous patterns. Most important, all of the elements of the mise-en-scène interact graphically to create an overall composition; characters do not simply exist within a setting, but rather form a visual element that merges with that setting" $(1986,354)$.

Logically, the wax images contribute a lot to encourage the deformative aspects, psychological as well as visual, which the film aims to achieve from this erratic flow of images. In a way, the wax statues serve both to alienate the viewer in the face of the atrocities committed by the figures portrayed in the three episodes, as well as to justify them. Harun Al-Rashid orders beheadings. Ivan the Terrible owns torture chambers. Jack the Ripper seeks to assassinate the writer himself. These are stories of violence, tragedy, jealousy and madness. Such degenerate subjects are processed by the wax figures in both the symbolic aspect (the crimes are committed, in the mind of the viewer, by mere images of images, non-living figures) and the historical one. Wax museums played an important role in the imaginary of the 1920s. Siegfried Kracauer, in his thorough evaluation of Weimar 
cinema through the theme of tyranny, also attributes to the wax figure a central role in the significance of Waxworks: "[t]he halo of unreality with which Leni surrounded the three episodes was the most appropriate, because these episodes carry as central figures the wax figures. These figures, in general, portray kings, murderers or heroes of the past - mimicking them to allow the contemporary to feel the shivers of terror or fear that they caused in their time. Their waxy appearance in an amusement park tent features Harun and Ivan like ghosts that are remote both in time and in relation to the real world" (Kracauer 2004, 104).

We must not forget that the three wax characters in the movie are clearly the image of their actors. Jannings, Veidt and Krauss were immediately recognizable celebrities to the audience back then. In that sense, the film may be regarded, in its most populist and media-typical configuration, as a kind of living wax statue museum in which Harun Al-Rashid and Emil Jannings can be viewed at the same time (and indistinguishably); as if the imaginary dimensions of history, society and media were intercommunicating interfaces. It is a multiple, simultaneous and indiscernible aspect of image, also impossible to represent exclusively through writing or speech. In each and any direction, therefore, the farce of the writer in Waxworks points to what he is not: first, the technical image of the movie, that seeks to falsify speech and writing; second, the imagination of the writer himself, guilty of the delirious deviations both in verisimilitude and in the constitution of ambience and settings in the story; and third, the consumable image of the star system of German silent film, also immediately transmittable, without the help of the codes that the movie seeks to parody. ${ }^{3}$

We do not go from the writer, from words and speech to get to silence and, especially, image, in vain. One need only remember that the movie itself gets resolved in much the same manner. After seeing the stories of the caliph and the Russian czar translated into images in the movie, we assume we are in for a viewing, also on a mise-en-abyme, the whole story of the British serial killer. However, that does not come to fruition. In just five minutes, the writer's farce is definitively denounced by the movie's narrative, which decides to undertake its own code, independent from the flow of image metamorphoses in operation when there was a hierarchy between the image of writing and the image of cinema. Thus, the writer, exhausted after writing overnight, falls asleep after he begins with Jack the Ripper's tale. What follows are the five most intense minutes of the

3 Just not to fail to mention a possible contradiction, the names of the actors were written in the placard the first time their image was shown, as was usual in silent movies at the time, but this does not invalidate the fact that the actors were recognized due to their immense popularity, especially due to their images. 
film, from an aesthetic point of view. The scene is almost entirely formatted as overprints and acts as a trigger for an imagistic unconscious onscreen, and reality gets indistinguishable from the writer's dream [Fig. 7]. What used to be linearity, narrative, affectation and farce, becomes an unbounded flow of images of Jack chasing the writer himself and his protégé. We not only lose track of time and space, but the movie scenery also accentuates the deformity of these. This time around, without the cognitive filter of words, the movie seems to say that finally that is what it is all about. It waxes about pure image; image without referent, murky, multiplied, the true nightmare of the word. The writer no longer yields a fumbling written discourse but something that stems directly from his unconscious mind. Once again, then, dream appears as a means for a primitive image, and the final message of the movie can hardly be interpreted otherwise. Thinking Jack had struck him, the writer jams the pen against his own chest [Fig. 8], materializing through this gesture the inefficacy of writing in silent movies. "That the writer, as he falls asleep, seems to 'stab' himself with his pen, only adds (a) further link to the chain of castration anxieties, but with a sarcastic-sadistic comment on the central conflict of the Kino-Debatte, namely the rearguard battle of the literary establishment - the writers - to retain their cultural capital, while some of their less high-minded colleagues are prepared to 'sell out' to the cinema, here once more, as in Dr Caligari, depicted as a fairground.” (Elsaesser 2000, 85-86.)

Finally, the ending of Waxworks allows us to draw a link between expressionist aesthetics, the Derridean trail and a theory of silent cinema. The expressionism (literal or parodic) of the film, in its deep connection with the natural transmutation of images, is the perfect environment for the diffusion of a deeper conflict. As it was put by Kracauer when discussing the film: "[b]ut what, in the frame-story, was nothing more than a place full of entertainment, is now a desert hunting ground for ghosts. Expressionist paintings, ingenious lighting effects and many other resources available in 1924 were used to create this eerie phantasmagoria, which substantiates the notion of chaos, in a way even stronger than the Caligari script" (Kracauer 2004, 105). The transformation of space in phantasmagoria serves as a bridge to think about image and silence as linked to the trail (which fades) originating from Derrida's archiscripture, placing them at the epicentre of a debate (on transmedia, as well) which also includes writing, sound and speech. In this sense, silent cinema, with all its idiosyncrasies, works as a media body that allows an open dialogue about these topics. This dialogue permeates philosophy and media theory, making contemporary study of silent film increasingly essential. 


\section{References}

Barnier, Martin. 2010. Bruits, cris, musiques de films: Les projections avant 1914. [Noise, Screams, Film Music. The Projections before 1914], Rennes: Presses Universitaires de Rennes.

Bordwell, David and Kristin Thompson. 1986 [1985]. Film Art. An Introduction. New York: Alfred A. Knopf.

Chion, Michel. 2005. L'audio-vision. Son et image au cinema. [Audio-vision. Sound on Screen], Paris: Armand Colin.

Derrida, Jacques. 1978 [1967]. Writing and Difference. Chicago: University of Chicago Press.

Derrida, Jacques. 1998 [1967]. Of Grammatology. Baltimore: Johns Hopkins University Press.

Eisner, Lotte. 2008 [1952]. The Haunted Screen: Expressionism in the German Cinema and the Influence of Max Reinhardt. Berkeley: University of California Press.

Elsaesser, Thomas. 2000. Weimar Cinema and After: Germany's Historical Imaginary. Abingdon: Routledge.

Garncarz, Joseph. 2004. Art and industry: German Cinema of the 1920s. In The Silent Cinema Reader, eds. Lee Grieveson and Peter Krämer, 389-400. New York: Routledge.

Gaudreault, André and François Jost. 2005 [1989]. Le Récit Cinématografique. Paris: Armand Colin.

Glenn, Cheryl. 2004. Unspoken: A Rhetoric of Silence. Carbondale: Southern Illinois University Press.

Johnson, Christopher. 2001 [1998]. Derrida. [Derrida: The Scene of Writing], São Paulo: Editora UNESP.

Kracauer, Siegfried. 2004 [1947]. From Caligari to Hitler: A Psychological History of the German Film, Princeton: Princeton University Press.

Kovadloff, Santiago. 2003 [1993]. O Silêncio Primordial. [Primordial Silence], Rio de Janeiro: José Olympio.

McLuhan, Marshall. 1994 [1964]. Understading Media: the Extentions of Man, Cambridge MA: MIT Press.

Raynauld, Isabelle. 2001. Dialogues in Early Silent Screenplays: What Actors Really Said. In The Sounds of Early Cinema, eds. Rick Altman and Richard Abel, 69-78. Bloomington: Indiana University Press. 
Szaloky, Melinda. 2002. Sounding Images in Silent Film: Visual Acoustics in Murnau's Sunrise. Cinema Journal vol. 41, no. 2 (Winter): 109-131.

\section{List of Figures}

Figure 1. The fairground and the tent with the wax statues.

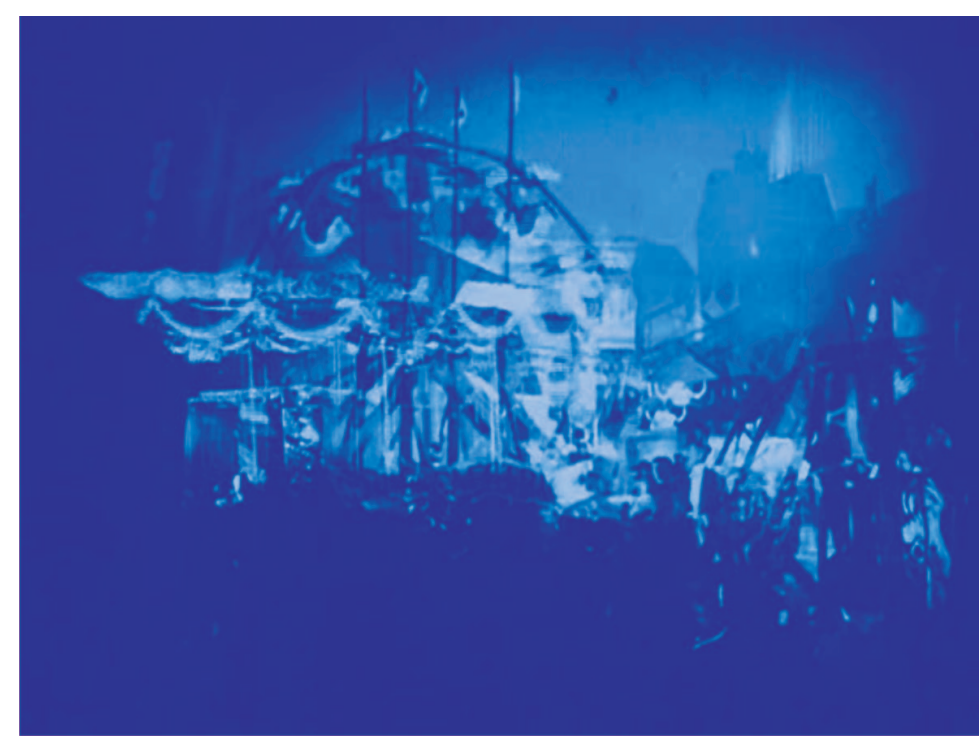

Figure 2. The writer, the owner of the tent and his daughter.

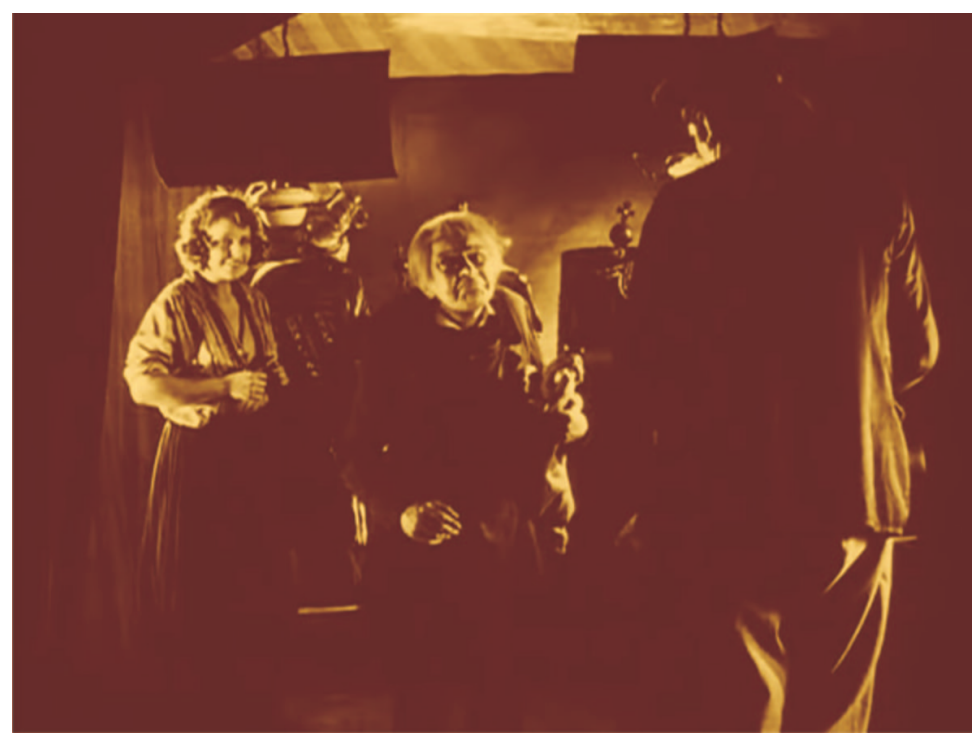


Figure 3. Harun Al-Rashid (Emil Jannings).

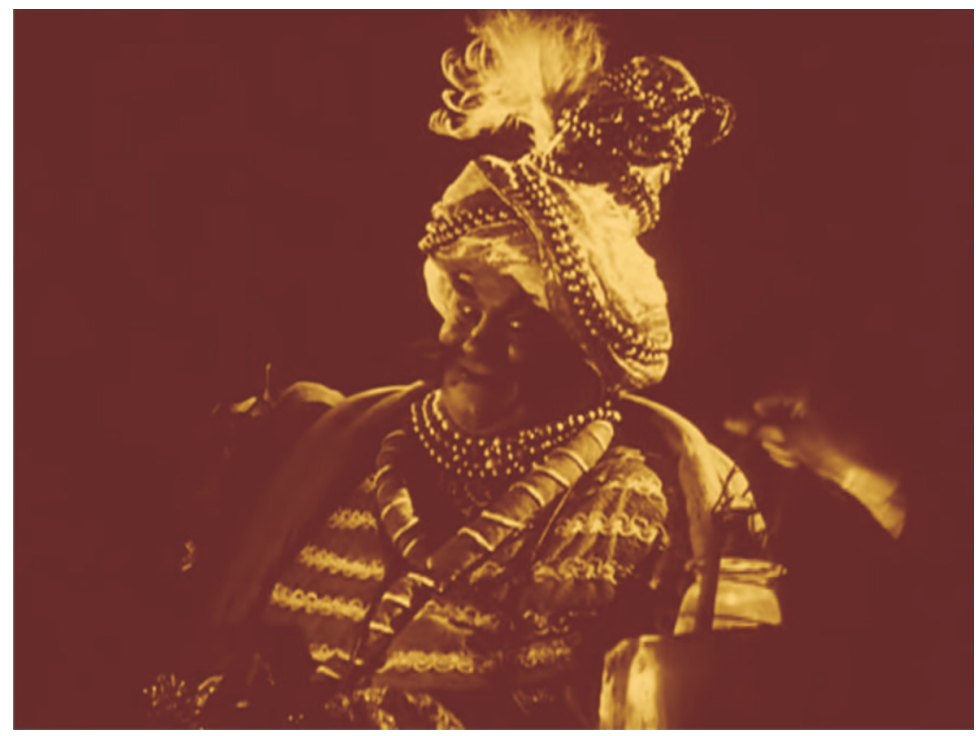

Figure 4. Ivan the Terrible (Conrad Veidt).

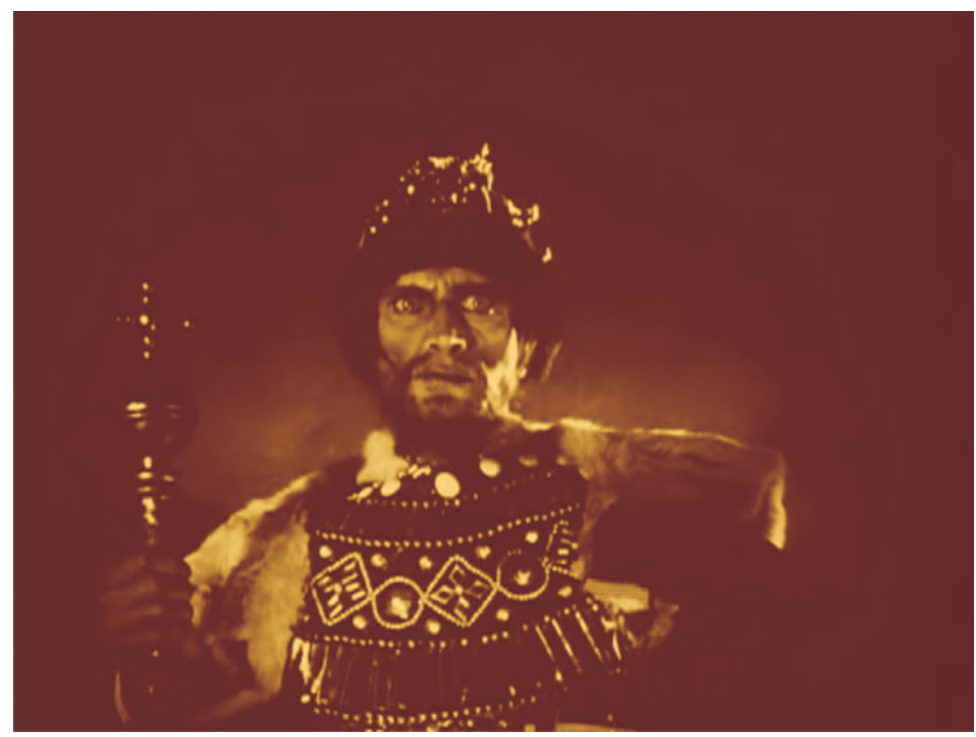


Figure 5. Jack the Ripper (Werner Krauss).

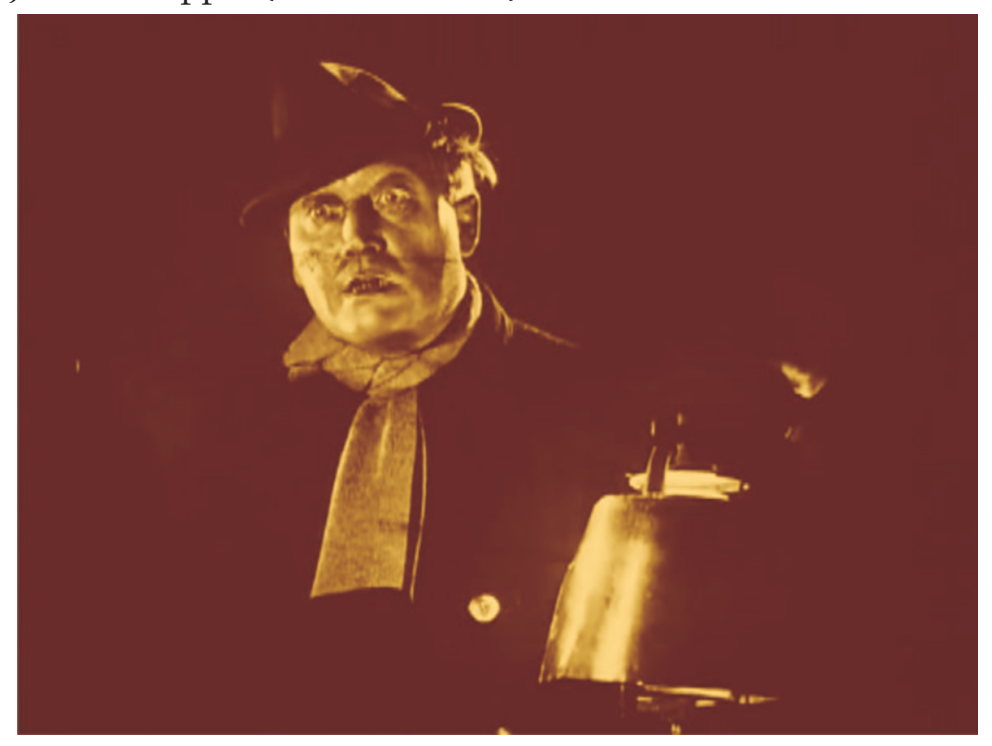

Figure 6. The writer produces a tale for each statue.

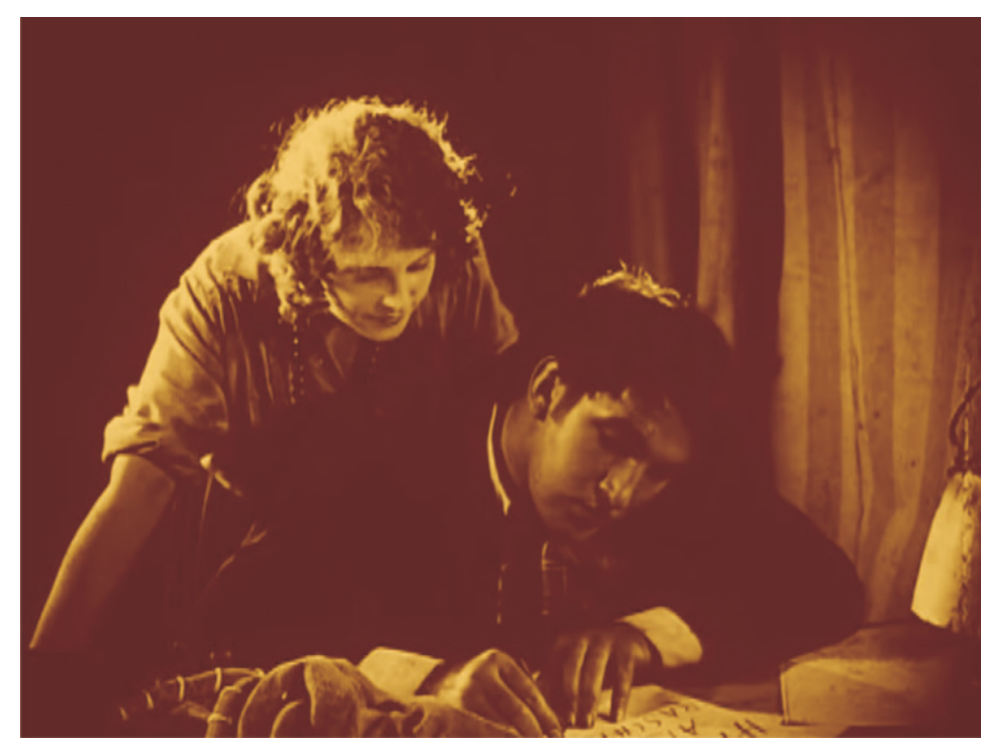


Figure 7. Dream and reality become indistinguishable.

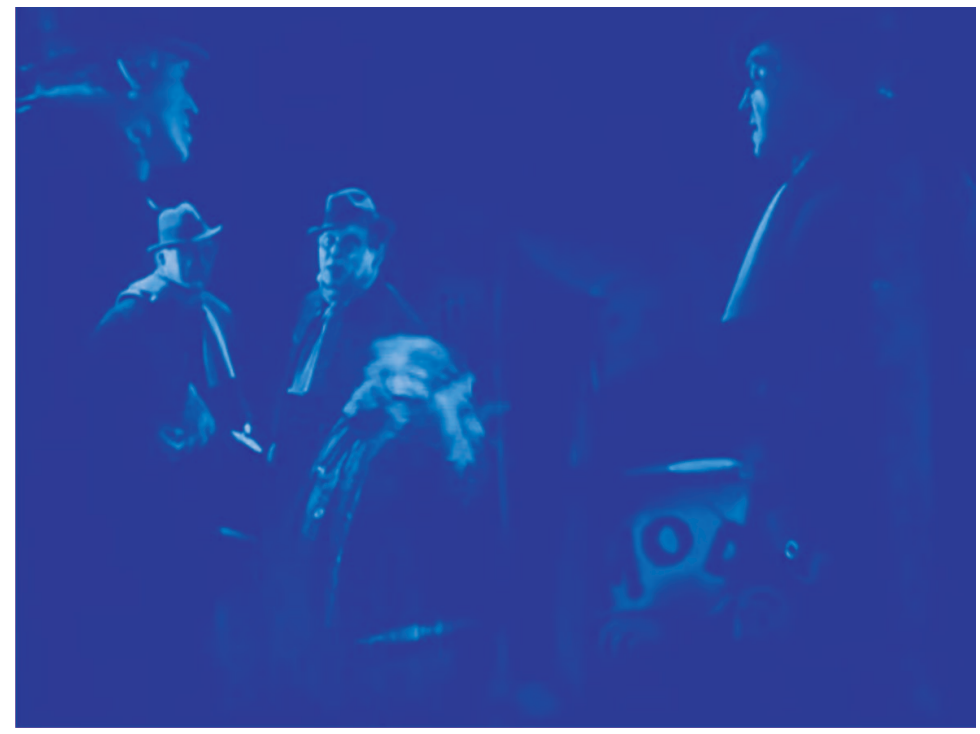

Figure 8. The writer thrusts the pen at his own chest.

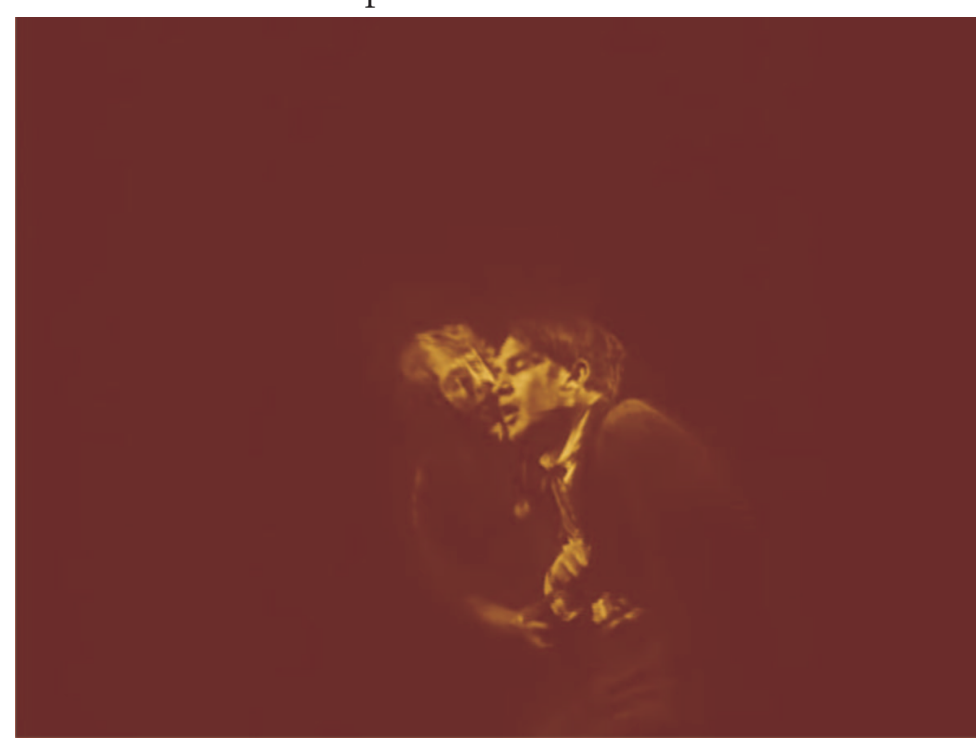

